\title{
LA POESIA INDIGENISTA DE VANGUARDIA DE ALEJANDRO PERALTA
}

Alejandro Peralta (1899-1973) es el más destacado del grupo de poetas peruanos que alrededor de 1926, en su empeño de crear una literatura nacional, utilizaron el paisaje y el hombre indígena como objeto de su poesía, por lo que se les llamó «indigenistas». Es decir, que el indigenismo de Peralta se inició como una rama del «nativismo», término usado por Luis Monguió en su obra La poesía posmodernista peruana, refiriéndose a «las varias escuelas literarias cuyas presuposiciones estéticas presentan el común denominador de pretender reflejar poéticamente la peculiaridad o peculiaridades peruanas, la peruanidad, según diversas interpretaciones etnográficas o telúricas» ${ }^{1}$.

En el primer libro indigenista de Peralta, Ande, de 1926, se habla, como sugiere el título, del paisaje serrano. El indio aparece, generalmente, como complemento de este paisaje. En el segundo libro, de 1934, titulado Kollao, nombre de la meseta del lago Titicaca, predomina la visión del indio con sus problemas vitales.

El aspecto más novedoso de la poesía indigenista de Peralta está en el uso de las técnicas vanguardistas. La visión poética se da en una sucesión de imágenes sintetizadas, utilizando el letrismo y suprimiendo la métrica, la rima y la puntuación. Este modo ha sido un obstáculo para la valorización objetiva de dicha poesía. Los críticos, en su mayor parte, opinan que el estilo vanguardista no se aviene a la literatura indigenista.

En su estudio del movimiento posmodernista del Perú, Monguió, con mesura, considera lógico que el indigenismo, movido por un impulso de renovación literaria, se endeudase con las escuelas vanguardistas, pero encuentra curioso, sin embargo, "que este inicial indigenismo, que teóricamente reclamaba el autoctonismo integral, hubiese echado mano de

${ }^{1}$ Luis Monguió, La poesía posmodernista peruana (Berkeley and Los Angeles: University of California Press, 1954), p. 87. Todas las referencias a Monguió se derivan de esta edición y damos la página en el texto. 
técnicas literarias comunes en las literaturas de otros países y otras escuelas» (p. 100), y considera la forma expresiva de la poesía indigenista de vanguardia «poco adecuada para provocar una respuesta emocional en la multitud peruana, porque el imaginismo y la metaforización sintéticos, vanguardistas..., requieren para su apreciación una sofisticación literaria ciertamente no multitudinaria en el Perú de aquellos, ni de estos, años» (p. 101). Sin embargo, en los Siete ensayos publicados por Mariátegui dos años después de la aparición del Ande de Peralta hay una defensa del incipiente indigenismo de vanguardia. Mariátegui entendía que teniendo el indigenismo fundamentalmente el sentido de una reivindicación de lo autóctono, no podía estar «desconectado» de los «elementos nuevos» de la hora, sino que, por el contrario, se encontraba articulado con ellos ${ }^{2}$.

La vinculación del indigenismo con los movimientos de vanguardia en el Perú es un caso notable. En su estudio «La recepción del surrealismo en el Perú», Estuardo Núñez describe la labor de Mariátegui en este particular ${ }^{3}$. Mariátegui presenció en Europa el surgimiento de los movimientos de vanguardia, y a su regreso al Perú, en 1923, siguió atento a ellos, concediendo «natural y especial atención a la aproximación del surrealismo a la actividad política» (p. 40). Como director de la revista Amauta, que apareció en 1926, estimuló el surgimiento de una generación peruana de surrealistas y vulgarizó el movimiento. Peralta fue uno de los colaboradores de Amauta e hizo papel principal en otra revista indigenista, de ultraístas de los de la región del Puno, adicta al vocabulario quechua-peruano, titulada Titikaka.

La aplicación de las técnicas de vanguardia al tema autóctono por los indigenistas peruanos es comparable al programa de americanización de los grandes escritores románticos hispanoamericanos, es decir, que Peralta, con su vanguardismo indigenista, responde más de lleno al esfuerzo de su época de crear una literatura autóctona. La literatura hispanoamericana llegó a ser eso cuando el escritor tomó conciencia de las peculiaridades de su territorio y lo expresó a la manera de la época. Por nostalgia del paisaje cubano, Heredia anticipó el romanticismo e influyó en la formación de la literatura cubana. Echeverría en la Argentina y León

${ }^{2}$ José Carlos Mariátegui, Siete ensayos de interpretación de la realidad peruana (Lima: Biblioteca Amauta, 1965). Véase XVII: «Las corrientes de hoy. El indigenismo», pp. 290 y 286.

${ }^{3}$ En Surrealismo/Surrealismos. Latinoamérica y España, Memorias del Congreso del Instituto Internacional de Literatura Iberoamericana, 24-29 de agosto de 1975. Peter G. Earle y Germán Gullón, Editores (Philadelfia: Department of Romance Languages, University of Pennsylvania). La página que se da en el texto es de esta edición. 
de Mera en el Ecuador recrearon el paisaje autóctono por el empeño de dar vida a una literatura nacional. En otras regiones de Hispanoamérica, hombre y paisaje aparecen vinculados en las primeras obras de carácter nacional; tal fue el caso en México, en El Periquillo Sarniento de Lizardi y El Zarco de Altamirano. En el Perú, como sabemos, el romanticismo no creó una literatura nacional. Las Tradiciones de Palma fueron una prolongación del criollismo iniciado durante la colonia en las obras de Caviedes, Terralla y Landa y Manuel Ascencio Segura. González Prada, iniciador del indigenismo, no sintió el paisaje, pese a sus indigenistas Baladas peruanas. Santos Chocano le cantó a las cosas autóctonas como espectador, sin identificarse con ellas. Peralta, sin ser de la talla de los autores mencionados, tiene la distinción de haber convertido lo autóctono, hombre y paisaje, en el objeto primordial de su poesía mejor. El viento, las rocas, los desfiladeros de su ambiente natal, el altiplano, aparecen como figuras de representación aun en sus poemas no indigenistas que describen estados de ánimo, como en "Invocación al viento», de la colección «Escarpas»:
El viento el hosco viento único amigo de mi prisión de solitario Vivo lo mismo que él golpeando las distancias a la siga del fuego de sus alas
Cimas desfiladeros precipicios ¿Serán minutos días años siglos los que me sobran o los que me faltan? ${ }^{4}$

En «Hombre altiplánico», de la misma colección, las figuras del objeto, que es el dolor de ser hombre, son tomadas del paisaje:
Es mi dolor la espalda ensangrentada es mi dolor endurecido en año madre de nieve y roca y cielo libre madre de azules vientos desatados (ibid., p. 68).

Peralta nació en la meseta del lago Titicaca y en su poesía se recrean los aspectos más armónicos de ese paisaje nativo, ya sea en descripción directa, como fondo natural de las cosas que en él se encuentran, o como término de comparación para expresar el amor o estados de ánimo. En

\footnotetext{
"Alejandro Peralta, «Escarpas», en Poesia de entretiempo (Lima: Ediciones Andimar, 1968), p. 64. Todos los poemas a los que nos referimos en este trabajo se encuentran en esta edición. Damos la página en el texto.
} 
Panorama actual de la poesía peruana, obra de 1938, Estuardo Núñez escribió que la mirada de Peralta «se circunscribe a la meseta del lago Titicaca y sus sensaciones están accionadas por un sentimiento de desolación y tristeza propio de esos parajes de [su] territorio» ${ }^{5}$. Por otro lado, Luis Alberto Sánchez, en su reciente Historia comparada de las literaturas americanas, dice que Peralta no hizo "concesiones a la tradicional melancolía india» ${ }^{6}$. Ambos críticos son peruanos. El lector no peruano, como en mi caso, menos comprometido con la realidad, llega a conclusiones diferentes. En mi opinión, Peralta mira con tanto amor el paisaje nativo que, pese a la dureza del medio, se le vuelven amables todas las visiones. De los veinte poemas del libro indigenista Ande, diez son expresiones jubilosas del amanecer o de las mañanas con sol. En «Cristales del Ande», por ejemplo, se habla del despertar de hombres y cosas en estos términos:

Titicaca Emperador

en los hombros su peplum de alas prusia

contempla el júbilo de sus marineros

y se limpia los tímpanos de un aluvión de trinos

Domingos de ojos saltarines

las calles vestidas de colores corren como culebras por la aldea

EL SOL

se ha desmenuzado como un desbande de canarios (p. 153).

Otro poema, «Amanecer», consiste de cinco versos juguetones celebrando la mañana:

\author{
Calles cortadas al rape \\ frescas \\ bajo el pulverizador de las brisas lacustres \\ La mañana está de bañera \\ y me han fletado un mameluco azul (p. 155).
}

El sentimiento de desolación no aparece en esta visión del pueblo, el apego de Peralta al ambiente nativo es obvio, por la insistencia en la designación directa de lo común exaltado en todos sus aspectos. «Balsas

\footnotetext{
${ }^{5}$ (Lima: Editorial Antina), p. 116.

' (Buenos Aires: Editorial Losada, 1976), tomo IV, «Del vanguardismo a nuestros días», p. 244.
} 
matinales» es una alegre visión de la salida de las balsas sobre el lago; en "Gotas de cromo» se sublima la visión de las gaviotas en la playa:

\author{
Las gaviotas bataclanas \\ vestidas de azahares \\ en el altar de la playa \\ comulgan con hostias de agua (p. 160).
}

Peralta ha convertido la espuma en azahares y hostias y ha sintetizado con acierto los conceptos de blancura y pureza propios del amanecer, que es la hora que se celebra en el poema.

Peralta se compenetra con el paisaje de tal modo que comunica el sentimiento de las cosas, como quien dice. El kolly es un árbol pequeñito del altiplano que resiste las embestidas del frío y el viento, y en el poema «El kolly» el hablante se duele de su situación:
Detrás de los galpones cenobiarcas el kolly atisba el cielo tiene curvadas las espaldas del peso de los cerros
Desde el amorotamiento de sus ojeras destila sobre las quemadas mejillas de la tierra un desvaído llanto de acuarelas (p. 177).

Aun los elementos menos amables de su ambiente son incorporados a la visión poética, creando graciosas imágenes, como en el poema «La pastora florida»:

Los ojos de la Antuca se empolvan al pasar por los galpones (p. 152).

Y de nuevo:

el barro de los fangos

ha ensuciado el camino bengala de sus ojos (p. 152).

Del paisaje se derivan las figuras de significación para describir a los habitantes del lugar. En «Chozas de mediodía» nos dice: «Fuertes indios pescadores / fornidas pantorrillas de peñones» (p. 162). Las mujeres son: «Venus de bronce, / ojos mojados de totorales, / frentes quemadas de relámpagos / piernas mordidas de peñascos» (en "Cristales del Ande», p. 154). En «El indio Antonio», el único poema trágico del libro Ande, en el que se habla de la muerte de la mujer de este indio, el ambiente se desarregla por interferencia del elemento discorde: 
Ha venido el indio Antonio el habla triturada los ojos como candelas EN LA PUERTA HA MANCHADO las CORTINAS DEL SOL (p. 169).

Después hay una gradación en el poema y los fenómenos naturales van acompasados a la tragedia:

la Francisca se retorció como un resorte mientras el granizo apedreaba la puna (ibíd.).

Finalmente, el ambiente se vincula a la tragedia:

Desde el vértice de las tapias aullará el perro al arenal del cielo de las cuevas de los cerros los indios sacarán rujidos como culebras (ibíd.).

Y así como el poema comienza con una imagen de luz desarreglada por el hombre, termina con una imagen deformativa de la noche:

A rastras sobre las pajas

la noche ronda el caserío (p. 170).

Es decir, que no se trata de un sentimiento de desolación y tristeza de parte del hablante, sino que el paisaje va haciéndose eco de una tragedia humana.

Aun en los poemas en que el hablante expresa estados de ánimo, las imágenes mantienen su congruencia, como se puede apreciar en los ejemplos que siguen. En el poema «Caminos», dice: «Sé que es inútil coger más plumas / de los pantanos llovidos / en todas las mañanas / no hemos hecho más que irnos» (p. 167). En «Andinismo», que trata del deseo de elevarse mental o espiritualmente, el altiplano proporciona las imágenes:

un huracán de espinos y árboles

hacia el océano de las cumbres

Erupción del vesubio del alma

LOS MARTILLOS DE LOS MONTES

SOBRE LOS YUNQUES PULMONARES (p. 159). 
Como se habrá notado, la poesía de Peralta no es hermética; el vocabulario es el poético tradicional, con peruanismos y palabras quechuas, más profusas en el segundo libro que en el primero. Tampoco hay en su poesía vanguardista violencias a la morfología, lo que se dice es siempre explícito, por la fiel correspondencia entre su mundo poético y su mundo nativo. El lago, los vientos, los cerros, además del muy apreciado sol, son los elementos más destacados de su poesía, con una diversidad de imágenes relacionadas a estos elementos a lo largo de toda la obra. Citamos: «Los vientos bajan a saltos de los cerros / bajan como tropeles de vicuñas» («Chozas de mediodía», p. 162); «Los vientos quiebran sus colmillos / en el frontal de la peñolería» («El kolly», p. 177); «Martín, el balsero del viento / azota el espinazo de las aguas / mientras el sol desde su aeronave / arroja bombas de magnesio» («Balsas matinales», p. 157).

La incorporación de la ideología indigenista en el sentido de reivindicación social en Kollao, el segundo libro de Peralta, es casi un deber. Según Tamayo Vargas en su estudio sobre Literatura peruana, hay una fuerte acentuación social y política en el Perú a partir del año $30{ }^{7}$ y se puede notar la tendencia humanista con preocupación por los problemas de la sociedad. Había quien creía, según Tamayo Vargas, que no era la hora propicia para la poesía, sino para el estudio social (ibíd.). En Kollao, Peralta responde a esta realidad histórica: de los veinticuatro poemas de esta obra, once exponen la situación angustiosa del habitante de la sierra, seis son estampas costumbristas, cinco hablan aún del paisaje y dos son poemas de amor. Sin embargo, pese al predominante tema de preocupación social, la visión del paisaje es aún armónica, la hora preferida sigue siendo el amanecer, exaltado en cuatro de los cinco poemas sobre el paisaje, y hay una gran utilización del vocabulario quechua para designar elementos de la flora y la fauna nativas y cosas locales, como los tipos, las casas, los instrumentos musicales, las fiestas.

Peralta, mejor poeta en ese segundo libro indigenista, consigue una mayor unidad de representación. En comparación con Kollao, algunos poemas de Ande parecen mero ejercicio vanguardista. Véase la diferencia en el tratamiento de un mismo motivo en dos descripciones del amanecer en que el hablante atraviesa el Ande a caballo. En el primer poema, del libro Ande, no nos enteramos de que el hablante es un jinete hasta el verso diez, completamente desligado de los anteriores:

${ }^{7}$ Augusto Tamayo Vargas, Literatura peruana (Lima: Universidad Nacional Mayor de San Marcos, 1965), tomo II, p. 808. 


\author{
Los gallos \\ engullen el maíz de la alborada \\ y acribillan de navajas polítonas \\ las carnes de la mañana \\ Wagner en caballerizas y establos \\ El pañuelo \\ de la mañana \\ limpia los ojos \\ de los viajeros
}

$\mathrm{Al}$ trote al trote por la acuarela del camino

(«Cristales del Ande», p. 153.)

La metáfora «las carnes de la mañana», en referencia al amanecer, es burda, le niega su cualidad de frágil y naciente; sin embargo, hay una sensación de fuerza en la estrofa, que se mantiene en el verso que sigue: "Wagner en caballerizas y establos», lograda frase para expresar la bulla no desarmónica de los animales; pero esta sensación de bruta armonía se pierde en los versos a continuación: «el pañuelo / de la mañana / limpia los ojos / de los viajeros». Monguió compara negativamente la retórica forzada de este poema con la fluidez de imágenes y metáforas de Vallejo (p. 104). Pero no hay que ir tan lejos, basta compararlo con otro poema del segundo libro, Kollao, en el que Peralta usa el mismo motivo: el hablante es un jinete, pero presentado como tal desde el primer verso, creándose a continuación una serie de imágenes sensoriales relacionadas con la cabalgata que insinúan fuerza y movimiento derivados de los elementos del paisaje. Nótense las logradas sinestesias de los dos primeros versos:

El silencio se desmorona frente a la cabalgata marejadas de relinchos brinca el amanecer sobre las peñas la aldea desnuda sus vértebras de piedra

la campana de la iglesia navega hacia la pampa

Bebemos el primer alcohol matinal

El sol está limpiando los tejados

en las crines de los caballos enredamos la alegría

E1 día va sujeto a los estribos

(«Travesía andinista», p. 109.) 
Se ve y se oye el progreso de la cabalgata, las escenas avanzan como en una película. Hay amplitud de visión y economía en versos, como el siguiente: «llevamos el paisaje sobre la grupa como un poncho de colores». La mención de los quehaceres del pueblo marca el paso del tiempo: por la mañana pasa un cortejo nupcial, viajeros por el mediodía, viajeros retrasados por la tarde. La premura de los jinetes a la caída de la noche está bien expresada en el verso: «El látigo de las riendas corta pedazos de neblina» (p. 110), y la visión de los campamentos en las alturas de los peñascos se sintetiza en otro logrado verso: «Fogones de anochecer llenan el cielo de farolas» (ibíd.).

Alberto Tauro, que ha estudiado El indigenismo a través de la poesía de Alejandro Peralta, señala dos momentos en ella: el primero es el de Ande, en el que el indio aparece como engarzado en el paisaje; el segundo es el de Kollao, en donde Peralta proyecta su atención hacia el valor humano ${ }^{8}$. Aida Cometta Manzoni concurre con esta opinión en su obra El indio en la poesía de América española. Pero el indio «engarzado en el paisaje» está también presente en Kollao, en el que Peralta hace poesía indigenista en el sentido de poesía autóctona, además de hacerla en el sentido en que la define Cometta Manzoni, es decir, tratando de llegar a la realidad del indio y ponerse en contacto con él hablando de sus luchas, su miseria, su dolor ${ }^{9}$. Firme a su voluntad de crear una literatura autóctona, Peralta sigue hablando del paisaje nativo cuando sirve a la causa del proletariado. En una nota biográfica citada por Estuardo Núñez, dice Peralta de su obra poética: «Hombre y paisaje expresan en ella una unidad de tragedia» ${ }^{10}$, y más tarde se refiere a un libro que va a escribir, «con tendencia al lenguaje popular y que siendo expresión de su personal tragedia, lo será también del pueblo a cuya raíz [pertenece]" (ibíd., p. 116). La integración de los dos indigenismos en la poesía de Peralta, es decir, el autóctono y el comprometido, se puede apreciar en dos poemas de Kollao con un mismo motivo. El objeto del primero es, como lo indica el título, «Jornaleras», y el del segundo, también indicado por el título, es «Canto obrero». En el primero el hablante dirige su atención al paisaje y al hombre como parte de él:

\section{EL SOL ORDENA LAS LABORES}

Los campesinos de Huaraya apuntalan las carpas del viento

Brazos y piernas vibrantes de cordajes en el gimnasio de la mañana

${ }^{8}$ (Lima: Compañía de Impresiones y Publicidad, 1935).

- Aida Cometta Manzoni, El indio en la poesía de América española (Buenos Aires: Joaquín Torres, Editor, 1939), p. 20.

${ }^{10}$ En Estuardo Núñez, Panorama actual de la poesía peruana, p. 115. 
Balseros del Ayllu

ya enarbolaron el arco del día en pleno lago

A lo largo del camino embanderado de rebozos

las frescas jornaleras del bajio

dale

que dale

a la bullanga

VIENEN DE ORDEÑAR EL ALBA (p. 116).

En el segundo poema lo importante es el obrero:

Mano apretada y magullada voz

Tú ensanchabas nuestro proletarismo

Golpe de pulmón

en el labio caído

tuviste hambre

y un hervor de días

en el recuerdo

Pegado al Tiempo y de mano con la Tierra

aquél te llenó de cicatrices ésta te endureció

Limpias paletadas de sol terraplenaron tu camino

$\mathrm{y}$ ágil de fresco viento y azul alegre

apenas un tenue perfume de pan te dio la vida (p. 138).

La amable visión de los elementos del paisaje nativo no ha cambiado: el sol conforta al obrero, el viento y el cielo lo hacen ágil. Con raras excepciones, hay en estos poemas indigenistas de Peralta un divorcio entre el paisaje y el habitante. En esta síntesis está su expresión mejor. En el poema «Exaltación del hijo», los libres bienes de la naturaleza redimen la miseria de los protagonistas:

No hay alcohol para el anafe de esta noche y no tenemos ni un centavo de alegría

Se ha extraviado la llave del sótano

donde acuñábamos las esterlinas de la aurora

Vamos a rasgar los horizontes como telarañas

Vamos a escarbar la tierra

No será para siempre

MAÑANA

el pequeñín

CORRETEARA ARRASTRANDO EL SOL POR LAS BALDOSAS (p. 145). 
En el poema «El indio Pako» hay prosaísmos de expresión que se salvan por la intercalación de imágenes identificando paisaje y habitante, como en los versos que siguen:

Toda la tierra es del patrón

Al pudridero el que se oponga

¿Quién defiende a los indios indio Pako?

LA CARA DEL INDIO PAKO ES UN PEÑON SOBRE LA PAMPa (p. 141).

Contrario a algunas obras indigenistas de preocupación social, en las que el indio parece que se disminuyera al ser victimizado por la sociedad, en el Kollao de Peralta el indio es un digno hombre del altiplano si la pugna es solamente con los elementos naturales. En «Trozo montañés» lo vemos cruzar firme la altipampa asaeteado de relámpagos:

En la altipampa con la lluvia cortada a pico pastor de relámpagos su firme paso matemático espanta las nubes frontal de fuego mordido de la serpiente en sus ojos chicotea el salto del tigre (p. 127).

En el agua también es este indio dueño de su ambiente:

La balsa del indio Kespe ha atravesado el lago como una flecha Nunca se siente más hombre

Es duro y petulante en la tormenta

y en el pueblo no para sino a la hora de alistar la marcha (p. 131).

Peralta pasó parte de su infancia entre Arequipa y Puno, su ciudad natal, y como recaudador de tributos llegó a conocer, según su propia declaración, «grandes extensiones de la meseta kollaviana» (en Panorama actual, p. 115). A raíz de la publicación de Ande, que fue muy bien recibido, pasó a vivir a Miraflores. En 1968 se volvió a hablar de él con la publicación de Poesía de entretiempo, que contiene los libros Ande y Kollao. En 1971 publicó Tierra-Aire, libro de muy variada métrica y contenido, que no aporta elementos nuevos a su poesía. Como dice César A. Rodríguez, que prologa la obra:

Permaneciendo casi invariable el fraseo de sus versos, lo que ha cambiado en él, ganando en magnitud su caudal poético, es el sentido combativo de los temas y su espontáneo abarcamiento. En ellos se fustiga, se increpa, se levanta el puño indignado y se clama justicia contra la pauperización de las masas proletarias y contra los genocidios 
que se llevan a cabo aún por los países acaparadores de los potenciales económicos y bélicos para sojuzgar a los países que insolentemente los apodan «subdesarrollados» ${ }^{11}$.

Lo mismo puede decirse de sus poemas póstumos Al filo del tránsito ${ }^{12}$. Ande y Kollao quedan como sus más grandes logros artísticos. Como dijera el mismo Peralta en un párrafo «Al lector» de Poesía de entretiempo, pidiéndole la frase prestada a Walt Whitman: "Quien lo(s) toca, toca a un hombre».

University of Maryland.

\section{Graciela Palau de Nemes}

1 Alejandro Peralta, Tierra-Aire (Lima: Librería Editorial «Minerva» Miraflores), pp. 11-12. Agradecemos a Cristina de Cornejo, de Lima, el habernos conseguido el ejemplar de este libro y del que se menciona a continuación.

12 Alejandro Peralta, Al filo del tránsito. Poemas póstumos (Lima: Ediciones Instituto Puneño de Cultura, 1974). En Historia comparada de las literaturas americanas, IV, 244, dice Luis Alberto Sánchez: «Su libro Ande (1926), al que sigute El Kollao (1934) y, ya en su ancianidad, Poesía extratemporal (1970), renovó el indigenismo peruano, dotándolo de vocabulario e imágenes novedosas y cosmopolitas». Una búsqueda de este último título a través del National Union Catalogue de la Biblioteca del Congreso y de las gestiones a nuestro favor de la señora de Cornejo, asesorada por el poeta Ernesto More, paisano de Peralta y «autor» del homenaje póstumo a su obra, ha resultado infructuosa. La obra Poesia de entretiempo de Peralta, de 1968, reúne las condiciones que Sánchez menciona de la no encontrada Poesía extratemporal. 